\title{
Identification of Leaf Rust Resistance Genes in Chinese Common Wheat Cultivars
}

Takele Weldu Gebrewahid, College of Agronomy, Agricultural University of Hebei/North China Key Laboratory for Crop Germplasm Resources, Baoding 071001, China; and College of Agriculture, Aksum University, Ethiopia; Zhan-Jun Yao ${ }^{\dagger}$ and Xiao-Cui Yan, College of Agronomy, Agricultural University of Hebei/North China Key Laboratory for Crop Germplasm Resources, Baoding 071001, China; and Pu Gao and Zai-Feng Li, ${ }^{\dagger}$ College of Plant Protection, Agricultural University of Hebei/Biological Control Center for Plant Disease and Pests of Hebei Province, Baoding 071001, China

\begin{abstract}
Puccinia triticina Eriks. (Pt), the causal agent of wheat (Triticum aestivum L.) leaf rust, is the most widespread disease of common wheat worldwide. In the present study, 83 wheat cultivars from three provinces of China and 36 tester lines with known leaf rust resistance $(L r)$ genes were inoculated in the greenhouse with 18 Pt pathotypes to identify seedling effective $L r$ genes. Field tests were also performed to characterize slow leaf rusting responses at the adult plant growth stage in Baoding and Zhoukou in the 2014-15 and 2015-16 cropping seasons. Twelve Lr genes, viz. Lr1, Lr26, Lr3ka, Lr11, Lr10, Lr2b, Lr13, Lr21, Lr34,

Lr37, Lr44, and Lr46 either singly or in combination were identified in 41 cultivars. Known $L r$ genes were not detected in the remaining 42 cultivars. The most commonly identified resistance genes were $\operatorname{Lr} 26(20$ cultivars), $L r 46$ (18 cultivars), and $L r l$ (eight cultivars). Less frequently detected genes included $\operatorname{Lr} 13, \operatorname{Lr} 34$, and $\operatorname{Lr} 37$ (each present in four cultivars), $L r 10$ (three cultivars), and $L r 3 k a$ and $L r 44$ (each in two cultivars). Evidence for the presence of genes $L r 11, L r 2 b$, and $L r 21$ (each in one cultivar) was also obtained. Seventeen cultivars were found to have slow rusting resistance in both field growing seasons.
\end{abstract}

Wheat leaf rust is one of the most important wheat diseases worldwide (Mebrate et al. 2008). It decreases grain quantity and quality, and can reduce production by $40 \%$ in susceptible cultivars (Khan et al. 2013). A severe leaf rust epidemic was reported in northwestern Mexico during 1976-77, which caused 70\% estimated yield losses (Dubin and Torres 1981). Four significant leaf rust epidemics were documented in China, in 1969, 1973, 1975, and 1979 (Dong 2001). During the past decade, leaf rust has periodically caused serious yield losses in the major Chinese wheat production regions (Zhao et al. 2008). High yield losses were recorded in 2012 in five provinces of China, viz. Gansu, Sichuan, Shanxi, Henan, and Anhui (Li et al. 2014; Zhou et al. 2013).

Resistant wheat cultivars are the most economical, effective, and environmentally friendly method for controlling leaf rust (Pink 2002). Identification of $L r$ gene(s) present in wheat cultivars aids in appropriate cultivar deployment to help control the disease. Gene postulation via multipathotype testing and molecular marker genotyping are useful methods to understand the $L r$ genes present in wheat cultivars.

Gene postulation based on the gene-for-gene hypothesis (Flor 1956) has been used by researchers to determine the $L r$ genes present in wheat cultivars. For instance, Hysing et al. (2006) postulated nine Lr genes ( Lr1, Lr2a, Lr3, Lr10, Lr13, Lr14a, Lr17, Lr23, and Lr26) from 84 wheat cultivars grown in Denmark, Finland, Norway, and Sweden using 12 pathotypes. McVey and Long (1993) identified $14 \mathrm{Lr}$ genes, viz. Lr1, Lr2a, Lr3, Lr3ka, Lr9, Lr10, Lr11, Lr14a, Lr16, Lr17a, Lr18, Lr24, Lr26, and Lr30 from 86 hard red winter wheat breeding lines using 17 Pt pathotypes. D. Singh et al. (2001) found that $L r 1, L r 3 a, L r 10, L r 13, L r 17 b, L r 20, L r 26$, and $L r 37$ were present in 70 U.K. wheat cultivars using six Pt pathotypes. $L r 1, L r 3 a$, Lr10, Lr13, Lr17b, Lr20, Lr26, Lr37, Lr3ka, and Lr14a were identified by Pathan and Park (2006) in 105 European wheat cultivars using five $P t$ pathotypes. Eight $L r$ genes $(L r 1, L r 3, L r 10, L r 13, L r 16$, $L r 17, L r 23$, and $L r 26$ ) were postulated from 22 Iraqi bread wheat cultivars with 13 Pt pathotypes (Maaroof et al. 2005). R. P. Singh and S. Rajaram (1991) identified 14 Lr genes (Lrl, Lr3, Lr3bg, LrlO, Lr13,

${ }^{\dagger}$ Corresponding authors: Z. J. Yao, E-mail: yzhj201@aliyun.com; and Z. F. Li, E-mail: 1zf7551@aliyun.com

Accepted for publication 4 June 2017.

(c) 2017 The American Phytopathological Society
Lrl4a, Lr16, Lr17a, Lrl9, Lr23, Lr26, Lr27 + Lr31, and Lr34) in 76 wheat cultivars from Mexico using $17 \mathrm{Pt}$ pathotypes. Mebrate et al. (2008) postulated $18 \mathrm{Lr}$ genes $(\mathrm{Lr} 1, \mathrm{Lr} 2 \mathrm{c}, \mathrm{Lr} 3, \mathrm{Lr} 3 \mathrm{ka}, \mathrm{Lr} 9, \mathrm{Lr} 10$, Lr14a, Lr14b, Lr13, Lr16, Lr18, Lr20, Lr21, Lr23, Lr27+31, Lr30, $\mathrm{Lr37}$, and Lr44) in 36 wheat cultivars from Ethiopia and Germany using $31 P t$ pathotypes. R. P. Singh et al. (1999) postulated nine $L r$ genes, namely Lr1, Lr3, Lr3bg, Lr10, Lr13, Lr14a, Lr16, Lr23, and Lr26 from 163 Chinese spring and winter wheat cultivars using $14 P t$ pathotypes. Li et al. (2010) identified $14 \mathrm{Lr}$ genes, viz. $\mathrm{Lrl}, \mathrm{Lr} 2 a, \mathrm{Lr} 3 b g$, Lr3ka, Lr14a, Lr16, Lr17a, Lr18, Lr20, Lr23, Lr24, Lr26, Lr34, and LrZH84 in 102 Chinese winter wheat cultivars using 24 Pt pathotypes.

To identify $L r$ genes more accurately and efficiently, increasingly molecular markers linked to such genes are being developed. For example, genes like Lrl (Cloutier et al. 2007), Lr9 (Gupta et al. 2005; Schachermayr et al. 1994), Lr10 (Schachermayr et al. 1997), Lr19 (Gupta et al. 2006b; Prins et al. 2001), Lr20 (Neu et al. 2002), Lr24 (Gupta et al. 2006a; Schachermayr et al. 1995), Lr26 (Chai et al. 2006; de Froidmont 1998; Mago et al. 2002), Lr34 (Dyck 1987), Lr37 (Bariana and McIntosh 1993), and Lr46 (R. P. Singh et al. 1998) can be identified by closely linked molecular markers.

To date, $76 \mathrm{Lr}$ genes have been formally cataloged in the wheat genome (McIntosh et al. 2016). Most of these are seedling resistance genes or major genes that are presumed to interact with $P t$ on a genefor-gene basis (McIntosh et al. 1995, 2003). However, host resistance conferred by major genes have a tendency to be easily overcome by new virulent rust pathotypes (McDonald and Linde 2002). Therefore, pyramiding several $L r$ genes into a single cultivar is a useful strategy as the combined effects of several genes give the cultivar a wider base of disease resistance, thereby extending the period of effectiveness (Roelfs et al. 1992). In recent years, only a few $\operatorname{Lr}$ genes, $\operatorname{Lr} 9$, $L r 19, L r 24$, and $L r 38$, have resistance against prevalent $P t$ pathotypes in China (Li et al. 2010; Yuan et al. 2007). Slow rusting genes or minor genes are more durable than the seedling resistance genes. The characteristics of minor genes include slow disease development in the field, longer latent period, low infection frequency, smaller pustule size, and less production of urediniospores (Caldwell 1968). Minor rust resistance genes in wheat are not only more durable but also have been found in some cases to have a pleiotropic effect on multiple diseases (Li et al. 2014; R. P. Singh 1992; Spielmeyer et al. 2005). Of the 76 Lr genes, Lr34 (Dyck 1987), Lr46 (R. P. Singh et al. 1998), Lr67 (Herrera-Foessel et al. 2011; Hiebert et al. 2010), and $\operatorname{Lr68}$ (Herrera-Foessel et al. 2012) are assumed to be slow rusting resistance genes. 
In China, there is little information on $L r$ genes present in wheat cultivars and this makes it difficult to manage resistant cultivars for controlling leaf rust. Therefore, identifying $L r$ genes in the currently released Chinese wheat cultivars is important for sustainable gene deployment and for breeding new resistant cultivars. This study was designed to identify the seedling and slow rusting resistance genes in 83 wheat cultivars from Jiangsu, Anhui, and Ningxia provinces in China.

\section{Materials and Methods}

Plant materials. Eighty-three wheat cultivars (Table 1) from Jiangsu, Anhui, and Ningxia provinces were selected to test their seedling responses to $18 \mathrm{Pt}$ pathotypes. Thirty-six differential lines, mostly near isogenic lines (NILs) in the background of Thatcher with known $\mathrm{Lr}$ genes provided by USDA-ARS Cereal Disease Laboratory, University of Minnesota, St Paul, U.S.A., were also tested.

Table 1. The pedigree and origin of 83 wheat cultivars tested for leaf rust response from three provinces in China

\begin{tabular}{|c|c|c|c|}
\hline Line & Genotype & Pedigree & Origin \\
\hline 1 & An 1331 & $\mathrm{NA}^{\mathrm{a}}$ & Anhui \\
\hline 2 & Annong 0305 & Aizao 781/Wansu 8802 & Anhui \\
\hline 3 & Fu 936 & $\begin{array}{l}\text { Wanmai } 20 / \text { Jimai } 5418 / / \text { Neixiang } \\
184\end{array}$ & Anhui \\
\hline 4 & Hua 2566 & $\begin{array}{l}\text { Een } 1 / \text { hua } 9528 / / \text { Jiayin } 175 / \\
\text { Chuannong } 6280\end{array}$ & Jiangsu \\
\hline 5 & Huaimai 18 & Zhengzhou 891/Yan 1604 & Jiangsu \\
\hline 6 & Huaimai 19 & NA & Jiangsu \\
\hline 7 & Huaimai 21 & Huaimai 17/Yumai 54 & Jiangsu \\
\hline 8 & Huaimai 25 & NA & Jiangsu \\
\hline 9 & Huaimai 30 & Zhengmai 9023/Huai 86175 & Jiangsu \\
\hline 10 & Lian 0536 & NA & Jiangsu \\
\hline 11 & Lian 0809 & NA & Jiangsu \\
\hline 12 & Lian 9791-4 & Jian 94/Lumai 21 & Jiangsu \\
\hline 13 & Lianmai 2 & Jian 94(73)/Lumai 21 & Jiangsu \\
\hline 14 & Nannong 02y293 & NA & Jiangsu \\
\hline 15 & Nannong 0686 & MV964 091×Ningmai 9 & Jiangsu \\
\hline 16 & Nannong 3519 & NA & Jiangsu \\
\hline 17 & Nannong 9918 & $\begin{array}{l}\text { Yangmai 158/92R137//Yangmai } \\
158\end{array}$ & Jiangsu \\
\hline 18 & Ningchun 10 & Yuzhonghong/Denong 3 & Ningxia \\
\hline 19 & Ningdong 1 & Changwu 7125/Jinnong 3 & Ningxia \\
\hline 20 & Ningdong 10 & $\begin{array}{l}\text { NZT/302//ALD/4/NAD//TMP/ } \\
\text { CI12426/3/EMU/5/Beinong } 2\end{array}$ & Ningxia \\
\hline 21 & Ningdong 11 & RENAN//Beinong 2 /Beijing 841 & Ningxia \\
\hline 22 & Ningdong 13 & Luo 9073 & Ningxia \\
\hline 23 & Ningdong 2 & Xifeng 18/CA8055 & Ningxia \\
\hline 24 & Ningdong 3 & Qingnong 3/Qingfeng 1 & Ningxia \\
\hline 25 & Ningmai 10 & Sha Shanghai 7//PRL"s"/VEE" & Jiangsu \\
\hline 26 & Ningmai 11 & Ningmai 8 & Jiangsu \\
\hline 27 & Ningmai 13 & Ningmai 9 & Jiangsu \\
\hline 28 & Ningmai 14 & Ningmai 9 & Jiangsu \\
\hline 29 & Ningmai 15 & Ningmai 8 & Jiangsu \\
\hline 30 & Ningmai 16 & Ningmai 8/Ningmai 9 & Jiangsu \\
\hline 31 & Ningmai 17 & Ning9529*2/Yangmai5 & Jiangsu \\
\hline 32 & Ningmai 18 & $\begin{array}{l}\text { Ningmai } 9 * 2 / / \text { Ningmai } 9 / \\
\text { Yangmai } 10\end{array}$ & Jiangsu \\
\hline 33 & Pengxuan 3 & NA & Ningxia \\
\hline 34 & Su 0663 & NA & Jiangsu \\
\hline 35 & Su 553 & Yannong 19/Su 1264 & Jiangsu \\
\hline 36 & Sumai 3 & Afu 98/Taiwan Xiaomai & Jiangsu \\
\hline 37 & Sunong 6 & NA & Anhui \\
\hline 38 & Wan 23094 & $\begin{array}{l}\text { Ji 845034/Wan 825508//Wan } \\
\text { 8656/Yang } 8617\end{array}$ & Anhui \\
\hline 39 & Wanmai 19 & Boai 7422/Yumai 2 & Anhui \\
\hline 40 & Wanmai 29 & Yili xiaomai/Afuleer & Anhui \\
\hline 41 & Wanmai 33 & Zhong 8131-1/Annong 8326 & Anhui \\
\hline 42 & Wanmai 38 & Yanzhong 114/85-15-9 & Anhui \\
\hline \multicolumn{4}{|c|}{ (continued in next column) } \\
\hline
\end{tabular}

All 85 genotypes, including Zhengzhou 5389 (Chinese susceptible check) and the CIMMYT line SAAR (resistant check) for slow rusting resistance, were tested in the field in the 2014-15 and 2015-16 cropping seasons.

$\boldsymbol{P t}$ pathotypes. To identify $\mathrm{Lr}$ genes in the wheat cultivars, $18 \mathrm{Pt}$ pathotypes were used to inoculate 36 differentials carrying the resistance genes $\mathrm{Lrl}, 2 \mathrm{a}, 2 \mathrm{c}, 3,9,16,24,26,3 \mathrm{ka}, 11,17,30, \mathrm{~B}, 10,14 \mathrm{a}$, $18,2 b, 3 b g, 13,14 b, 15,19,20,21,23,28,29,33,36,39,42,44,45$, 47, 51, and 53 (Table 2). The $P t$ pathotypes were sourced from the culture collection from the Department of Plant Pathology, Agricultural University of Hebei, China. Fresh inoculum was obtained by multiplying urediniospores on the susceptible cultivar, Zhengzhou 5389. These pathotypes were named following the Prt code system described by Long and Kolmer (1989), with the addition of a fourth letter for the reactions to the fourth quartet of differentials (https://www.ars.usda gov/ARSUserFiles/50620500/Cerealrusts/pt_nomen.pdf).

Table 1. (continued from preceding column)

\begin{tabular}{|c|c|c|c|}
\hline Line & Genotype & Pedigree & Origin \\
\hline 43 & Wanmai 46 & Shan 7859/83(165) & Anhui \\
\hline 44 & Wanmai 47 & $\begin{array}{l}\text { Wanxi 8906//Boshou 7422/ } \\
\text { Ningmai } 3\end{array}$ & Anhui \\
\hline 45 & Wanmai 50 & Zhengzhou 8329/Wanmai 19 & Anhui \\
\hline 46 & Wanmai 52 & Zhengzhou 8329/Wanmai 1 & Anhui \\
\hline 47 & Wanmai 53 & Yumai 29/Wanmai 19 & Anhui \\
\hline 48 & Wanmai 68 & Wanmai 19/Zheng 79201 & Anhui \\
\hline 49 & Wansu 9908 & Bo 74-22/Yumai 2 & Anhui \\
\hline 50 & Xu 9069 & NA & Jiangsu \\
\hline 51 & Xu 9128 & NA & Ningxia \\
\hline 52 & Xumai 24 & 7924-13-2-2/Aimengniu & Jiangsu \\
\hline 53 & Xumai 25 & 7904-13-2-2/Bainong 792 & Jiangsu \\
\hline 54 & Xumai 26 & Xiaoyan 6/Shan 7859 & Jiangsu \\
\hline 55 & Xumai 27 & Zaofeng 1/Yan 1934 & Jiangsu \\
\hline 56 & Xumai 29 & Zhengzhou 8329/Zhoumai 9 & Jiangsu \\
\hline 57 & Xumai 30 & Zhou91098/Xuzhou 25 & Jiangsu \\
\hline 58 & Xumai 31 & Yanfu 188/Xuzhou 26 & Jiangsu \\
\hline 59 & Xumai 4036 & Yangfu188/xuzhou26 & Jiangsu \\
\hline 60 & Xuzhou 14 & Zaoyangmai/Nangda 2419 & Jiangsu \\
\hline 61 & Xuzhou 23 & $\begin{array}{l}\text { Punong 3665/UP301//Zhengzhou } \\
761\end{array}$ & Jiangsu \\
\hline 62 & Xuzhou 25 & 7904-13-2-2/Bainong 792 & Jiangsu \\
\hline 63 & Xuzhou 438 & Land race & Jiangsu \\
\hline 64 & Yangfumai 2 & Yangmai 158/101-90 & Jiangsu \\
\hline 65 & Yangfumai 3 & Yangmai 158/1-9012 & Jiangsu \\
\hline 66 & Yangfumai 4 & Ningmai 8/Ningmai 9 & Jiangsu \\
\hline 67 & Yangmai 10 & $\begin{array}{l}\text { Yuma/8*Cc//Yangmai 5/3/ } \\
4 * \text { Yang } 85-85 / 4 / 2 * \text { Yangmai } \\
158\end{array}$ & Jiangsu \\
\hline 68 & Yangmai 11 & $\underset{85}{\text { Yang 158/3Y.C/Jianer//Yang 85- }}$ & Jiangsu \\
\hline 69 & Yangmai 12 & $\begin{array}{l}\text { Yangmai 158/3/TP114/Yangmai } \\
\text { 5//85-853 }\end{array}$ & Jiangsu \\
\hline 70 & Yangmai 13 & $\begin{array}{l}\text { Yang 88-84//Yangmai 8/ } \\
\text { Maristdove }\end{array}$ & Jiangsu \\
\hline 71 & Yangmai 158 & Yangmai 4/ST 1472/506 & Jiangsu \\
\hline 72 & Yangmai 16 & Yang 91F138/Yang 90-30 & Jiangsu \\
\hline 73 & Yangmai 17 & 92F101/Chuanyu 21256 & Jiangsu \\
\hline 74 & Yangmai 19 & $\begin{array}{l}\text { Yangmai 96/4/Yang 158/3/4×Y. } \\
\text { C/Yangmai 5//85-854 }\end{array}$ & Jiangsu \\
\hline 75 & Yangmai 4 & Nanda 2419/Shenglimai/Axuan 2 & Jiangsu \\
\hline 76 & Yangmai 5 & $9-16-4 / \mathrm{St} 1472 / 506$ & Jiangsu \\
\hline 77 & Yangmai 9 & Jian 2/Jian 3 & Jiangsu \\
\hline 78 & Zhen 02168 & Sumai 6/97G59 & Jiangsu \\
\hline 79 & Zhen 05185 & Sumai 6/97G59 & Jiangsu \\
\hline 80 & Zhen 06101 & Yangmai15 & Jiangsu \\
\hline 81 & Zhenmai 168 & Sumai 6/97G59 & Jiangsu \\
\hline 82 & Zhenmai 6 & Yangmai 158/Zhenmai 1 & Jiangsu \\
\hline 83 & $209-1-2-1$ & NA & Jiangsu \\
\hline
\end{tabular}

${ }^{\mathrm{a}} \mathrm{NA}=$ Not available 
Seedling testing. A total of 83 cultivars, Zhengzhou 5389, and 36 differential lines were tested using 18 Pt pathotypes. Five to eight seeds of each were sown in a plastic growth chamber $(3 \times 2 \mathrm{~cm})$. Inoculation of seedlings was carried out by the method provided by $\mathrm{Li}$ et al. (2010) and R. P. Singh et al. (1999). Infection types (ITs) were recorded 10 to 14 days after inoculation based on the 0 to 4 Stakman scale modified by Roelfs et al. (1992) where $0=$ immune, ; = hypersensitive flecks with necrosis, 1 = small uredinia surrounded by necrosis, $2=$ small to medium uredinia surrounded by necrosis, $X=$ random distribution of variable-sized uredinia, $3=$ moderate size uredinia that may be associated with chlorosis, $4=$ large uredinia without chlorosis, $+=$ uredinia somewhat larger than normal, - = uredinia somewhat smaller than normal, and $\mathrm{C}=$ more chlorosis than normal. The gene postulation was conducted using the method reported by Dubin et al. (1989).

Field testing. All 85 genotypes, including Zhengzhou 5389 and SAAR, were evaluated for leaf rust reaction in the field nurseries at Baoding in Hebei Province and Zhoukou in Henan Province in the 2014-15 and 2015-16 wheat cropping seasons. Field tests were conducted in randomized complete blocks with two replicates at each location. Seeds (50 to 100 in number) of each cultivar were sown in single rows (1.5-m length and $25 \mathrm{~cm}$ between rows). The susceptible genotype Zhengzhou 5389 was sown adjacent and perpendicular to the test rows in order to aid the spread of spores within the trials. Epidemics were initiated by spraying aqueous suspensions containing equal amounts of mixed $P t$ pathotypes THTT, THTS, and FHTT to which a few drops of Tween $20(0.03 \%)$ were added, onto the spreader rows at tillering stage. Three $P t$ pathotypes, THTT, THTS, and FHTT, were virulent pathotypes to most of the 83 tested cultivars at the seedling stage in the greenhouse (Table 3). Four weeks after inoculation, leaf rust severity was scored once a week using the modified scale by Peterson et al. (1948). The ITs to the mixed pathotype were scored on a 0 to 4 scale as reported by Roelfs et al. (1992). The final disease severity (FDS, \%) data, when the susceptible check (Zhengzhou 5389) displayed maximum disease severity, was used for statistical data analysis.

Statistical analysis. Analysis of variance (ANOVA) was performed using the generalized linear model procedure (PROC GLMMIX) of Statistical Analysis System (version 9.1; SAS Institute Inc., Cary, NC). Cultivars, environments (the combination of location and year), and their interaction were treated as fixed effects, and replications nested in environments were as random. Fisher's least significant difference (LSD) test at $P=0.05$ was used to separate the treatment means (Sokal and Rohlf 1989) of FDS data. Genotypes with high ITs to mixed $P t$ pathotypes at the seedling stage and low FDS values (nonsignificantly higher FDS value than the slow rusting check, SAAR) in the field were considered to have slow rusting resistance.

DNA extraction and molecular marker detection. Genomic DNA of the cultivars was extracted according to the modified CTAB method (Gill et al. 1991; Ren et al. 2015). Twelve STS and SCAR markers for 10 known $\operatorname{Lr}$ genes, viz. Lr1, Lr9, Lr10, Lr19, Lr20, $L r 24, L r 26, L r 34, L r 37$, and $L r 46$, were utilized to test all cultivars. The sequences and annealing temperatures of all primers are provided in Table 4. PCR was performed following the protocol of Helguera et al. (2003). The PCR product was separated on a $1.5 \%$

Table 2. Infection types ${ }^{\mathrm{a}}$ of 36 tester lines inoculated with 18 Puccinia triticina Eriks (Pt) pathotypes

\begin{tabular}{|c|c|c|c|c|c|c|c|c|c|c|c|c|c|c|c|c|c|c|c|}
\hline \multirow[b]{3}{*}{ No. } & \multirow{3}{*}{$\begin{array}{l}\text { Leaf rust resistance } \\
(L r) \text { genes }\end{array}$} & \multicolumn{18}{|c|}{ Infection types to $P t$ pathotypes } \\
\hline & & $\mathbf{F H}$ & TH & TH & $\mathbf{F H}$ & $\mathbf{P H}$ & $\mathbf{P H}$ & FH & $\mathbf{P H}$ & $\mathbf{K H}$ & PH & TH & PH & FH & FH & FH & TG & FH & FG \\
\hline & & $\overline{\mathbf{P R}}$ & $\overline{\mathrm{JS}}$ & $\overline{\text { TS }}$ & $\overline{J Q 1}$ & $\overline{\mathrm{SL}}$ & $\overline{\mathrm{JT}}$ & $\overline{\mathrm{JQ2}}$ & $\overline{\text { SS }}$ & $\overline{\text { SS }}$ & $\overline{\text { TT1 }}$ & $\overline{\text { TT }}$ & $\overline{\text { TT2 }}$ & $\overline{\text { TR }}$ & $\overline{\text { HT1 }}$ & $\overline{\text { HT2 }}$ & $\overline{\text { GT }}$ & $\overline{\text { TT }}$ & $\overline{\mathrm{MT}}$ \\
\hline 1 & RL6003 (Lr1) & $; 1$ & 4 & 4 & 1 & 4 & 3 & 1 & 4 & $; 1$ & 4 & 4 & 4 & 1 & 1 & 1 & 4 & 1 & 1 \\
\hline 2 & RL6016 (Lr2a) & 2 & $3 c$ & $3+$ & 1 & ; & 2 & 2 & 1 & 4 & 1 & 4 & 1 & ; & 1 & 1 & 4 & ; & 1 \\
\hline 3 & RL6047 ( Lr2C) & 4 & 4 & 4 & 3 & $3+$ & 4 & 4 & 4 & 4 & 4 & 4 & 4 & 3 & 4 & 4 & 3 & 3 & 4 \\
\hline 4 & RL6002 (Lr3) & 4 & 3 & 4 & 4 & $3+$ & 4 & 4 & 4 & 4 & 4 & 4 & 4 & 4 & 4 & 4 & 3 & 4 & 4 \\
\hline 5 & RL6010 (Lr9) & 0 & 0 & 0 & 0 & 0 & 0 & 0 & 0 & 0 & 0 & 0 & 0 & 0 & 0 & 0 & 0 & 0 & 0 \\
\hline 6 & RL6005 (Lr16) & 3 & 4 & $3+$ & 4 & $3+$ & 4 & 4 & 3 & 4 & 3 & 4 & 3 & 3 & 3 & 3 & 3 & 3 & 3 \\
\hline 7 & RL6064 (Lr24) & ; & ; & ; & ; & ; & ; & $; 1$ & ; & ; & ; & ; & ; & ; & ; & ; & ; & 0 & 0 \\
\hline 8 & RL6078 (Lr26) & 3 & $3+$ & 4 & 4 & 4 & 3 & $3+$ & 3 & 3 & 3 & 3 & 3 & 3 & 3 & 3 & 2 & 3 & 2 \\
\hline 9 & RL6007 (Lr3ka) & 3 & 1 & $3+$ & 2 & $3+$ & 2 & 12 & 3 & 3 & 3 & 3 & 3 & 3 & 2 & 2 & 1 & 3 & 3 \\
\hline 10 & RL605 (Lr11) & 2 & $3+$ & 4 & 4 & 4 & 4 & 3 & 3 & 3 & 4 & 4 & 3 & 4 & 3 & 3 & 3 & 3 & 2 \\
\hline 11 & RL6008 (Lr17) & 3 & 4 & 4 & 3 & 4 & 3 & $3-$ & 3 & 3 & 3 & 4 & 3 & 3 & 2 & 1 & 2 & 3 & 2 \\
\hline 12 & RL6049 (Lr30) & 4 & 1 & $3+$ & 1 & $2+$ & 2 & 12 & 2 & 2 & 3 & 4 & 4 & 4 & 3 & 4 & 1 & 3 & 4 \\
\hline 13 & RL6051 ( $\operatorname{LrB})$ & 4 & 4 & 4 & 4 & $3+$ & 4 & 4 & 4 & 3 & 4 & 4 & 3 & 4 & 4 & 3 & 4 & 3 & 4 \\
\hline 14 & RL6004 (Lr10) & 4 & $3+$ & 4 & 3 & 2 & 4 & 4 & 4 & 4 & 4 & 3 & 4 & 3 & 3 & 3 & 4 & 4 & 4 \\
\hline 15 & RL6013 (Lr14a) & $\mathrm{X}$ & $3 c$ & $3+$ & 2 & $2 \mathrm{X}$ & 3 & $2 X$ & 3 & 3 & 4 & 3 & 4 & $\mathrm{X}$ & 3 & 3 & 3 & 3 & 3 \\
\hline 16 & RL6009 (Lr18) & 3 & $2+$ & 2 & 2 & $2+$ & 3 & 12 & 2 & 2 & 4 & 4 & 4 & 3 & 4 & 4 & 3 & 4 & 3 \\
\hline 17 & RL6019 $(L r 2 b)$ & 3 & 4 & $3+$ & 2 & $2+$ & 3 & 4 & 1 & 3 & 3 & 4 & 3 & 3 & 3 & 3 & 3 & 4 & 3 \\
\hline 18 & RL6042 (Lr3bg) & 4 & 3 & 4 & 4 & 4 & 3 & $3+$ & 4 & 3 & 4 & 4 & 3 & 3 & 3 & 3 & 3 & 4 & 4 \\
\hline 19 & RL4031 (Lr13) & 3 & 3 & 3 & 3 & $3+$ & 3 & $3+$ & 4 & 3 & 3 & 4 & 2 & 3 & 2 & 3 & 3 & 2 & 2 \\
\hline 20 & RL6006 (Lr14b) & 4 & 4 & 4 & 4 & 3 & 4 & 4 & 4 & 4 & 4 & 4 & 3 & 4 & 4 & 3 & 4 & 4 & 4 \\
\hline 21 & RL6052 (Lr15) & 2 & 1 & 3 & 1 & 4 & ;4 & 1 & 4 & 1 & 1 & 4 & 1 & 3 & 1 & 1 & 1 & 2 & 12 \\
\hline 22 & RL6040 (Lr19) & 0 & 0 & 0 & 0 & 0 & 0 & 0 & 0 & 0 & 0 & 0 & ; & 0 & ; & 0 & 0 & 0 & 0 \\
\hline 23 & RL6092 (Lr20) & $; 1$ & 1 & 3 & 1 & $3+$ & 1 & $; 1$ & 1 & 1 & 3 & 1 & 4 & 0 & 3 & 1 & 3 & 3 & 1 \\
\hline 24 & RL6043 (Lr21) & 3 & 3 & 4 & 4 & 2 & 3 & $3+$ & 4 & 3 & 3 & 3 & 3 & 3 & 4 & 3 & 2 & 3 & 2 \\
\hline 25 & RL6012 (Lr23) & 3 & 3 & 4 & 3 & 32 & 3 & 12 & $3-$ & 3 & 3 & 1 & 1 & 1 & 1 & 1 & 3 & $?$ & 1 \\
\hline 26 & RL6079 (Lr28) & 0 & 0 & 0 & 0 & 0 & 0 & 0 & 0 & 0 & ; & 0 & ; & 0 & ; & 0 & 0 & ; & ; \\
\hline 27 & RL6080 (Lr29) & 1 & 12 & 12 & 2 & 12 & 1 & 2 & 1 & 2 & 1 & 2 & $; 4$ & 2 & 3 & 3 & 1 & 3 & 2 \\
\hline 28 & RL6057 (Lr33) & 4 & 4 & 4 & $3+$ & $3+$ & 4 & 4 & 4 & $3+$ & 4 & 4 & 4 & 3 & 3 & 3 & 3 & 3 & 3 \\
\hline 29 & $\mathrm{E} 84018(\operatorname{Lr} 36)$ & 1 & $3 c$ & 2 & 1 & 2 & 12 & 1 & 12 & 12 & 3 & 1 & 2 & 1 & 1 & 1 & 3 & 1 & 1 \\
\hline 30 & KS86NGRC02 (Lr39) & 2 & 12 & 0 & 12 & $3-$ & 12 & 12 & $2+$ & 1 & 4 & 4 & 3 & 3 & 2 & 2 & 4 & 1 & 1 \\
\hline 31 & KS91WGRC11 (Lr42) & 2 & ; & 12 & ; & 4 & 4 & 1 & 1 & 3 & 1 & 1 & 2 & 2 & 2 & 3 & 1 & $3+$ & 3 \\
\hline 32 & RL6147 (Lr44) & $3+$ & $3+$ & 3 & 3 & 1 & 3 & 3 & $2+$ & 3 & 4 & 4 & 4 & 4 & 4 & 3 & 3 & 4 & 4 \\
\hline 33 & RL6144 (Lr45) & 4 & 4 & 4 & 4 & 4 & $3+$ & 4 & 4 & 4 & 1 & 1 & 1 & 1 & 1 & 1 & 3 & 1 & 1 \\
\hline 34 & PAVON76 (Lr47) & 0 & 0 & 0 & 0 & 0 & 0 & 0 & 0 & 0 & ; & 0 & ; & ; & ; & ; & ; & 0 & ; \\
\hline 35 & C78.5 (Lr51) & $; 1$ & ; & ; & ; & ; & 1 & $; 1$ & ; & ; & 1 & 1 & ; & 1 & 1 & ; & 1 & 1 & ; \\
\hline 36 & 98M71 (Lr53) & 0 & 0 & 0 & 0 & 0 & 0 & 0 & 0 & 0 & ; & 0 & ; & ; & ; & ; & ; & ; & 0 \\
\hline
\end{tabular}

\footnotetext{
${ }^{a}$ According to the 0-4 Stakman scale modified by Roelfs et al. (1992).
} 
agarose gel in $1 \times$ TAE buffer and stained with ethidium bromide, then photographed under UV light.

\section{Results}

$L r$ genes from seedling reactions and molecular marker detection. Seedling genes were postulated in the 83 wheat cultivars based on the comparison of ITs of the genotypes tested to ITs of 36 differentials with known $L r$ genes. Variations of ITs on the 36 differentials inoculated with $18 P t$ pathotypes (Table 2) indicated the possibility of postulating $22 \mathrm{Lr}$ genes, namely $L r 1, L r 2 a, L r 2 b, L r 3 k a, L r 10, L r 11$, Lr13, Lr14a, Lr15, Lr17, Lr26, Lr30, Lr18, Lr20, Lr21, Lr23, Lr29, Lr36, Lr39, Lr42, Lr44, and Lr45. Seven genes (Lr9, Lr24, Lr19,

Table 3. Seedling infection types ${ }^{\mathrm{a}}$ and presence or absence of leaf rust resistance $(L r)$ genes in 83 wheat cultivars collected from three provinces in China based on gene postulation using 18 Puccinia triticina Eriks. (Pt) pathotypes and molecular markers

\begin{tabular}{|c|c|c|c|c|c|c|c|c|c|c|c|c|c|c|c|c|c|c|c|}
\hline \multirow[b]{3}{*}{ Line no. ${ }^{b}$} & \multirow[b]{3}{*}{$L r$ gene } & \multicolumn{18}{|c|}{ Infection types to $P t$ pathotypes } \\
\hline & & FH & TH & TH & FH & PH & PH & FH & PH & KH & PH & TH & PH & FH & FH & FH & TG & FH & FG \\
\hline & & $\overline{\mathbf{P R}}$ & $\mathbf{J S}$ & TS & $\overline{\mathrm{JQ1}}$ & $\overline{S L}$ & $\mathbf{J T}$ & $\overline{\mathrm{JQ2}}$ & SS & SS & TT1 & TT & $\overline{\text { TT2 }}$ & TR & $\overline{\text { HT1 }}$ & $\overline{\text { HT2 }}$ & $\overline{\text { GT }}$ & $\overline{T T}$ & MT \\
\hline 1 & - & 4 & 4 & 4 & 4 & 4 & 4 & 4 & 4 & 4 & 4 & 3 & 4 & 3 & 4 & 4 & $3+$ & $3+$ & $3+$ \\
\hline 2 & - & 4 & 4 & 4 & 4 & 4 & 4 & 4 & 4 & 4 & 4 & 4 & 4 & 4 & 3 & $3+$ & 4 & 4 & 4 \\
\hline 3 & - & 4 & 4 & 4 & 4 & 4 & 4 & 4 & 4 & 4 & 4 & 4 & 3 & 3 & 4 & 4 & 3 & 4 & 3 \\
\hline 4 & - & 4 & 4 & 4 & 4 & 4 & 4 & 4 & 4 & 4 & 4 & 4 & 4 & 4 & 4 & 4 & $3+$ & $3+$ & 4 \\
\hline 5 & $\operatorname{Lr} 26^{\mathrm{c}}$ & 4 & 4 & 4 & 4 & 4 & 4 & 4 & 4 & 4 & 3 & 4 & 4 & 3 & 3 & 3 & 2 & 3 & 2 \\
\hline 6 & $L r I^{\mathrm{c}}$ & 1 & 4 & 4 & 1 & 4 & 4 & 0 & 4 & 1 & 4 & 3 & 4 & 2 & 1 & 1 & 4 & ; & $2+$ \\
\hline 7 & $\begin{array}{l}L r 1^{\mathrm{c}} \\
L r 26^{\mathrm{c}} \\
L r 3 k a^{\mathrm{d}} \\
L r 13^{\mathrm{d}+}\end{array}$ & 1 & 1 & 1 & 1 & $3-$ & 2 & 0 & 4 & 1 & 0 & 1 & 0 & $2+$ & ; & 1 & 2 & 0 & 2 \\
\hline 8 & $\operatorname{Lr} 26^{\mathrm{c}}$ & 4 & 4 & 4 & 4 & 4 & 4 & 4 & 4 & 4 & 3 & 4 & $3+$ & 3 & 3 & 3 & 2 & $3+$ & 1 \\
\hline 9 & - & 4 & 4 & 4 & 4 & 4 & 4 & 4 & 4 & 4 & 4 & 3 & $3+$ & 4 & 4 & 4 & 3 & 3 & 3 \\
\hline 10 & $\begin{array}{l}L r 1^{\mathrm{c}} \\
\operatorname{Lr} 26^{\mathrm{c}}\end{array}$ & 1 & 4 & $3 \mathrm{c}$ & 1 & 4 & 2 & ;1 & $3 c$ & 1 & 4 & 4 & $3+$ & 3 & 1 & 1 & 2 & 0 & 1 \\
\hline 11 & $\begin{array}{l}\operatorname{Lr} 26^{\mathrm{c}} \\
\operatorname{Lr} 34^{\mathrm{e}}\end{array}$ & 4 & 4 & 4 & 4 & 4 & 4 & 4 & 4 & 4 & $3+$ & 3 & $3+$ & 3 & $3+$ & 3 & 2 & 4 & 2 \\
\hline 12 & $\operatorname{Lr} 26^{\mathrm{c}}$ & 4 & 4 & 4 & 4 & 4 & 4 & 4 & 4 & 4 & 3 & 4 & $3+$ & 3 & 3 & 3 & 2 & $3+$ & 2 \\
\hline 13 & $\operatorname{Lr} 26^{\mathrm{c}}$ & $3+$ & 4 & 4 & 4 & 4 & 4 & 4 & 4 & 4 & 4 & 4 & 3 & 3 & 3 & 3 & 2 & $3+$ & 1 \\
\hline 14 & - & 4 & 4 & 4 & 4 & 4 & 4 & 4 & 4 & 4 & 4 & $3+$ & 4 & 4 & $3+$ & 3 & 4 & $3+$ & 3 \\
\hline 15 & $\begin{array}{l}L r 37^{\mathrm{e}} \\
L r 46^{\mathrm{e}}\end{array}$ & 4 & 4 & 4 & 4 & 4 & $3+$ & 4 & 4 & 4 & 3 & 4 & 4 & 4 & 4 & 4 & 4 & $3+$ & $3+$ \\
\hline 16 & $\begin{array}{l}L r 1^{\mathrm{c}} \\
L r 26^{\mathrm{c}} \\
L r 3 k a^{\mathrm{d}} \\
L r 13^{\mathrm{d}+}\end{array}$ & 12 & 1 & 2 & 1 & 3 & 12 & 12 & $3+$ & 2 & $3+$ & 3 & 2 & 1 & 1 & 1 & 2 & 1 & 1 \\
\hline 17 & - & 4 & 4 & 4 & 4 & 4 & 4 & 4 & 4 & 4 & 4 & 4 & 4 & 3 & 4 & 4 & 3 & 3 & 3 \\
\hline 18 & $L r 46^{\mathrm{e}}$ & 4 & 4 & 4 & 4 & 4 & 4 & 4 & 4 & 4 & $3+$ & $3+$ & 3 & 4 & $3+$ & 3 & 3 & 3 & 3 \\
\hline 19 & $L r 46^{\mathrm{e}}$ & $3+$ & 4 & 4 & 4 & 4 & 4 & 4 & 4 & 4 & 4 & $3+$ & 3 & 3 & 3 & 3 & 3 & $3+$ & 3 \\
\hline 20 & $L r 46^{\mathrm{e}}$ & $3+$ & 4 & $3+$ & 4 & 4 & 4 & 4 & 4 & 4 & $3+$ & 4 & 4 & $3+$ & $3+$ & 4 & 3 & 3 & 3 \\
\hline 21 & - & 4 & 4 & 4 & 4 & 4 & 4 & 4 & 4 & 4 & 4 & $3+$ & 3 & 4 & 3 & 3 & $3+$ & 3 & 3 \\
\hline 22 & - & $3+$ & 4 & 4 & 4 & 4 & 4 & 4 & 4 & 4 & 3 & 4 & 4 & 3 & $3+$ & 3 & 3 & 3 & 3 \\
\hline 23 & - & $3+$ & 4 & 4 & 4 & 4 & 4 & 4 & 4 & 4 & $3+$ & $3+$ & 4 & 4 & $3+$ & 3 & $3+$ & 3 & 3 \\
\hline 24 & $\begin{array}{l}L r 2 \sigma^{\mathrm{c}} \\
L r 46^{\mathrm{e}}\end{array}$ & 4 & 4 & 4 & 4 & 4 & $3+$ & 4 & 4 & 4 & $3+$ & $3+$ & $3+$ & 4 & $3+$ & 3 & 2 & 3 & 1 \\
\hline 25 & $L r 46^{\mathrm{e}}$ & 4 & 4 & 4 & 4 & 4 & 4 & 4 & 4 & 4 & 4 & 4 & 3 & 4 & $3+$ & $3+$ & $3+$ & $3+$ & 3 \\
\hline 26 & $\begin{array}{l}L r 26^{\mathrm{c}} \\
L r 46^{\mathrm{e}}\end{array}$ & $3+$ & $3 c$ & $3+$ & 4 & 4 & 4 & 4 & 4 & 4 & 3 & 3 & 3 & 3 & $3-$ & 3 & 2 & 3 & 1 \\
\hline 27 & $L r 46^{\mathrm{e}}$ & 4 & 4 & 4 & 4 & 4 & 4 & 4 & 4 & 4 & 4 & 4 & 3 & 4 & 4 & 4 & 4 & 3 & 3 \\
\hline 28 & - & 4 & 4 & 4 & 4 & 4 & 4 & 4 & 4 & 4 & 4 & 4 & $3+$ & 3 & 4 & 4 & $3+$ & 4 & $3+$ \\
\hline 29 & $L r 46^{\mathrm{e}}$ & 4 & 4 & 4 & 4 & 4 & 4 & 4 & 4 & 4 & 4 & 4 & 3 & $3+$ & 4 & 3 & 3 & 3 & 3 \\
\hline 30 & $L r l^{\mathrm{c}}$ & 1 & 4 & 4 & 1 & 4 & 4 & ; & 4 & 1 & 4 & 4 & 4 & 2 & 1 & 1 & 4 & 1 & 2 \\
\hline 31 & $L r 46^{\mathrm{e}}$ & 4 & 4 & 4 & 4 & 4 & 4 & $3+$ & 4 & 4 & $2+$ & 4 & $3+$ & 3 & 12 & 1 & $3+$ & 4 & $3+$ \\
\hline 32 & - & $3+$ & 4 & 4 & 4 & 4 & 4 & 4 & 4 & 4 & $3+$ & $3+$ & 4 & $3+$ & 3 & 3 & 3 & $3+$ & 3 \\
\hline 33 & $\begin{array}{l}L r 34^{\mathrm{e}} \\
L r 46^{\mathrm{e}}\end{array}$ & 4 & 4 & 4 & 4 & 4 & 4 & 4 & 3 & 4 & 3 & 3 & $3+$ & 3 & 3 & 3 & 3 & 3 & 3 \\
\hline 34 & - & $3+$ & 4 & 4 & 4 & 4 & 4 & 4 & 4 & 4 & 2 & 4 & 4 & $3+$ & 4 & 4 & 4 & $3+$ & 3 \\
\hline 35 & $\begin{array}{l}L r l^{\mathrm{c}} \\
\operatorname{Lr} I^{\mathrm{d}}\end{array}$ & 1 & 4 & 4 & 1 & 4 & 3 & ;1 & 3 & 1 & 4 & 4 & $3 c$ & 2 & 1 & 1 & 4 & 0 & 1 \\
\hline 36 & $\begin{array}{l}L r 34^{\mathrm{e}} \\
L r 46^{\mathrm{e}}\end{array}$ & 4 & $3+$ & 4 & 4 & 4 & 4 & $3+$ & 4 & 4 & 4 & 4 & 3 & $3+$ & 3 & 3 & $3+$ & 3 & 4 \\
\hline 37 & $L r I^{\mathrm{c}}$ & 1 & 4 & $3+$ & 1 & 3 & $3+$ & 0 & 4 & 1 & $3+$ & 3 & 3 & 1 & 2 & & $\begin{array}{c}2 \\
\text { inued }\end{array}$ & $\begin{array}{c}1 \\
n n e_{x}\end{array}$ & $\begin{array}{c}2 \\
\text { page })\end{array}$ \\
\hline
\end{tabular}

a According to the 0-4 Stakman scale as modified by Roelfs et al. (1992).

${ }^{\mathrm{b}}$ Line numbers correspond to those in Table 1.

c Postulation of $L r$ genes based on gene postulation and molecular marker.

d Postulation of $L r$ genes based on gene postulation.

${ }^{e}$ Detection of $L r$ genes based on molecular marker. 
Lr28, Lr47, Lr51, and Lr53) had low ITs to all the 18 Pt pathotypes. High ITs were noted with most of the pathotypes for $L r$ genes, viz. $L r 2 c, L r 3, L r 16, L r B, L r 3 b g, L r 14 b$, and $L r 33$, hence, it was impossible to postulate these genes.
The susceptible check Zhengzhou 5389 conferred a high (susceptible) IT 4 to all pathotypes. Based on the ITs of the 83 wheat cultivars inoculated with the $18 P t$ pathotypes (Table 3), nine $L r$ genes, $L r 1, L r 26$, $L r 3 k a, L r 11, L r 10, L r 2 b, L r 13, L r 21$, and Lr44 either singly or in

Table 3. (continued from preceding page)

Infection types to $P t$ pathotypes

$\begin{array}{llllllllllllllllllll}\text { Line no. } & L r \text { gene } & \frac{\text { FH }}{\text { PR }} & \frac{\text { TH }}{\text { JS }} & \frac{\text { TH }}{\text { TS }} & \frac{\text { FH }}{\text { JQ1 }} & \frac{\text { PH }}{\text { SL }} & \frac{\text { PH }}{\text { JT }} & \frac{\text { FH }}{\text { JQ2 }} & \frac{\text { PH }}{\text { SS }} & \frac{\text { KH }}{\text { SS }} & \frac{\text { PH }}{\text { TT1 }} & \frac{\text { TH }}{\text { TT }} & \frac{\text { PH }}{\text { TT2 }} & \frac{\text { FH }}{\text { TR }} & \frac{\text { FH }}{\text { HT1 }} & \frac{\text { FH }}{\text { HT2 }} & \frac{\text { TG }}{\text { GT }} & \frac{\text { FH }}{\text { TT }} & \frac{\text { FG }}{\text { MT }}\end{array}$

$\operatorname{Lr} 26^{\mathrm{c}}$

$\operatorname{Lr} 37^{\mathrm{e}}$

\begin{tabular}{|c|c|c|c|c|c|c|c|c|c|c|c|c|c|c|c|c|c|c|}
\hline 38 & - & $3+$ & 4 & 4 & 4 & 4 & 4 & 4 & 4 & 4 & 4 & 4 & 4 & 4 & 4 & 4 & 4 & $3+$ \\
\hline 39 & - & $3+$ & 4 & 4 & 4 & 4 & 4 & 4 & 4 & 3 & 4 & 3 & 3 & 3 & $3+$ & 3 & $3+$ & 4 \\
\hline 40 & - & $3+$ & 4 & 4 & 4 & 4 & 4 & $3+$ & 4 & 4 & $3+$ & 3 & $2+$ & $3+$ & 4 & 3 & 4 & $3+$ \\
\hline 41 & $\begin{array}{l}\operatorname{Lr} 10^{\mathrm{c}} \\
\mathrm{Lr} 44^{\mathrm{d}}\end{array}$ & 4 & 4 & 4 & 4 & 2 & 4 & 3 & $2+$ & 4 & 4 & 2 & $2+3-$ & 2 & 3 & 1 & $33 c$ & $3+$ \\
\hline 42 & - & 4 & 4 & 4 & 4 & 4 & 4 & 4 & 4 & 4 & 3 & 3 & $3+$ & $2+$ & 3 & 3 & 4 & 3 \\
\hline 43 & $\operatorname{Lr} 26^{\mathrm{e}}$ & $3+$ & 4 & 4 & 4 & 4 & 4 & 4 & 4 & $3+$ & 4 & 4 & $3+$ & $3+$ & $3+$ & 4 & 2 & 3 \\
\hline 44 & $\begin{array}{l}\operatorname{Lr} 26^{\mathrm{c}} \\
\operatorname{Lr} 10^{\mathrm{c}} \\
\operatorname{Lr} 2 b^{\mathrm{d}} \\
\operatorname{Lr} 21^{\mathrm{d}} \\
\operatorname{Lr} 44^{\mathrm{d}}\end{array}$ & 3 & 4 & 4 & 1 & 1 & 2 & ;1 & 12 & 1 & $3+$ & 4 & 3 & 3 & $2+$ & 3 & 1 & 1 \\
\hline 45 & - & $3+$ & 4 & 4 & 4 & 4 & 4 & 4 & 4 & 4 & 4 & 3 & 3 & $3+$ & $3+$ & 4 & 3 & 3 \\
\hline 46 & - & $3+$ & 4 & 4 & 4 & 4 & 4 & 4 & 4 & 4 & 4 & $3+$ & 3 & 3 & 4 & 3 & $3+$ & 3 \\
\hline 47 & - & 4 & 4 & 4 & 4 & 4 & 4 & 4 & 4 & 4 & 4 & 3 & 4 & 4 & $3+$ & 3 & $3+$ & 3 \\
\hline 48 & - & $3+$ & 4 & 4 & 4 & 4 & $3+$ & 4 & 4 & 4 & 4 & 3 & $3+$ & 4 & 4 & 4 & 4 & 3 \\
\hline 49 & - & 4 & 4 & 4 & 4 & 4 & 4 & 4 & 4 & 4 & $3+$ & 4 & 4 & 3 & $3+$ & 3 & $3+$ & 3 \\
\hline 50 & $\operatorname{Lr} 26^{\mathrm{c}}$ & 4 & 4 & 4 & 4 & 4 & 4 & 4 & 4 & 4 & 3 & 4 & $3+$ & 3 & 3 & 3 & 2 & $3+$ \\
\hline 51 & $\operatorname{Lr} 46^{\mathrm{e}}$ & 4 & 4 & 4 & 4 & 4 & 4 & 3 & 4 & 4 & 3 & 3 & 4 & 3 & 3 & 3 & 3 & $3+$ \\
\hline 52 & - & 4 & 4 & 4 & 4 & 4 & 4 & 4 & 4 & 4 & $3+$ & 4 & 3 & 3 & $3+$ & 3 & 3 & $3+$ \\
\hline 53 & - & 4 & 4 & 4 & 4 & 4 & 4 & 4 & 4 & 4 & 4 & 4 & 3 & 3 & 3 & 3 & 3 & 3 \\
\hline 54 & $\operatorname{Lr} 26^{\mathrm{c}}$ & 4 & 4 & 4 & 4 & 4 & 4 & 4 & 4 & 3 & 3 & $3+$ & 3 & $3-$ & 3 & 3 & 2 & 4 \\
\hline 55 & - & 4 & 4 & 4 & 4 & 4 & 4 & 4 & 4 & 4 & 3 & 4 & 4 & $3+$ & 3 & 3 & $3+$ & $3+$ \\
\hline 56 & $\operatorname{Lr} 26^{\mathrm{c}}$ & 4 & 4 & 4 & 4 & 4 & 4 & 4 & $3+$ & 4 & 4 & $3+$ & 4 & 3 & 4 & 3 & 2 & $3+$ \\
\hline 57 & - & 2 & 4 & 4 & 4 & 4 & 4 & 4 & 4 & 4 & 4 & 4 & 3 & $3+$ & $3+$ & 4 & $3+$ & 3 \\
\hline 58 & + & $3 c$ & 4 & 12 & 12 & $3 c$ & $2+$ & 12 & $2+$ & 12 & 2 & $2+$ & 2 & 3 & 2 & 1 & $3+$ & $3 c$ \\
\hline 59 & $\begin{array}{l}\operatorname{Lr} 10^{\mathrm{c}} \\
+\end{array}$ & 1 & 4 & 12 & 1 & 2 & $2+$ & 1 & 3 & 1 & $3+$ & 4 & $2+$ & 3 & 1 & 2 & $3+$ & 3 \\
\hline 60 & - & 4 & 4 & 4 & 4 & 4 & 4 & 4 & 4 & 4 & 3 & 4 & 4 & 4 & 4 & 4 & 4 & $3+$ \\
\hline 61 & $\begin{array}{l}\operatorname{Lr} 1^{\mathrm{c}} \\
\operatorname{Lr} 26^{\mathrm{c}} \\
\operatorname{Lr} 37^{\mathrm{e}}\end{array}$ & 1 & 4 & 4 & 1 & 4 & $3+$ & 1 & 4 & 0 & 4 & 4 & 4 & 2 & 1 & 1 & 2 & ; \\
\hline 62 & - & $3+$ & 4 & 4 & 4 & 4 & 4 & 4 & 4 & $3+$ & 4 & 3 & 3 & 3 & 3 & 3 & $3+$ & 3 \\
\hline 63 & $\begin{array}{l}\operatorname{Lr} 34^{\mathrm{e}} \\
\operatorname{Lr} 46^{\mathrm{e}}\end{array}$ & 4 & 4 & 4 & 4 & $3+$ & 4 & 4 & 4 & 4 & 4 & 4 & 4 & $3+$ & 4 & 3 & $3+$ & 3 \\
\hline 64 & $\begin{array}{l}\operatorname{Lr} 46^{\mathrm{e}} \\
\operatorname{Lr} 13^{\mathrm{d}}\end{array}$ & 4 & 4 & 4 & 4 & 4 & 4 & $3+$ & 4 & 4 & $2+$ & $3+$ & 2 & 12 & 1 & 1 & 4 & 2 \\
\hline 65 & $\begin{array}{l}\operatorname{Lr} 26^{\mathrm{c}} \\
\operatorname{Lr} 13^{\mathrm{d}}\end{array}$ & $3+$ & 4 & 4 & 4 & 4 & 4 & 4 & 4 & 4 & 3 & $3+$ & 2 & 2 & 2 & 4 & 2 & $2+$ \\
\hline 66 & - & 4 & 4 & 4 & 4 & 4 & 4 & 4 & 4 & 4 & 4 & 4 & 4 & 3 & $3+$ & 3 & 3 & 4 \\
\hline 67 & - & 4 & 4 & 4 & 4 & 4 & 4 & 4 & 4 & 4 & $3 c$ & 4 & 3 & 3 & 3 & 4 & 3 & $3+$ \\
\hline 68 & $\operatorname{Lr} 46^{\mathrm{c}}$ & 4 & 4 & 4 & 4 & 4 & 4 & 4 & 4 & 4 & 4 & $3+$ & 3 & $3 c$ & $3+$ & 4 & 3 & 3 \\
\hline 69 & - & 4 & 4 & 4 & 4 & 4 & $3+$ & 4 & 4 & 4 & 4 & 3 & 3 & 3 & 4 & 2 & 3 & 4 \\
\hline 70 & - & 4 & 4 & 4 & 4 & 4 & 4 & 4 & 4 & 4 & 4 & 4 & $2+$ & $2+$ & 4 & 2 & $3+$ & 3 \\
\hline 71 & $\operatorname{Lr} 26^{\mathrm{c}}$ & 4 & 4 & 4 & 4 & 4 & 4 & $3+$ & 4 & 4 & 3 & $3+$ & $2+$ & 3 & 3 & 3 & 2 & $3+$ \\
\hline 72 & - & 4 & 4 & 4 & 4 & 4 & 4 & 4 & 4 & 4 & 4 & $3+$ & $3+$ & 4 & 4 & 4 & 3 & 3 \\
\hline 73 & - & 4 & 4 & 4 & 4 & 4 & 4 & 4 & 4 & 4 & 4 & 4 & 3- & 4 & 4 & 3 & $3+$ & 3 \\
\hline 74 & - & 4 & 4 & 4 & 4 & 4 & 4 & 4 & 4 & 4 & 4 & 4 & $3+$ & 4 & 4 & 4 & 3 & 4 \\
\hline 75 & - & $3+$ & 4 & 4 & 4 & $3+$ & 4 & 4 & 3 & 4 & 4 & 3 & 3 & $2+3-$ & $3+$ & 3 & $3+$ & 3 \\
\hline 76 & - & 4 & 4 & 4 & 4 & 4 & 4 & 4 & 4 & 4 & $3+$ & 3 & 3 & 3 & 4 & 3 & $3+$ & 3 \\
\hline 77 & - & 4 & 4 & 4 & 4 & 4 & 4 & 4 & 4 & 4 & 4 & 4 & $3+$ & 4 & 4 & 3 & 4 & $3+$ \\
\hline 78 & - & 4 & 4 & 4 & 4 & 4 & 4 & 4 & 4 & 4 & 4 & 4 & $3+$ & 3 & 4 & 3 & 4 & 4 \\
\hline 79 & - & 4 & 4 & 4 & 4 & 4 & 4 & 4 & 4 & 4 & 4 & 4 & 4 & 3 & 4 & 3 & 3 & $3+$ \\
\hline 80 & - & 4 & 4 & 4 & 4 & 4 & 4 & 4 & 4 & 4 & 4 & 4 & $3+$ & 4 & 4 & 4 & 4 & $3+$ \\
\hline 81 & $\begin{array}{l}\operatorname{Lr} 37^{\mathrm{e}} \\
L r 46^{\mathrm{e}}\end{array}$ & 4 & 4 & 4 & 4 & 4 & 4 & 4 & 4 & 4 & 4 & 4 & 4 & 4 & $3+$ & 4 & 3 & 3 \\
\hline 82 & - & 4 & 4 & 4 & 4 & 4 & 4 & 4 & 4 & 4 & 4 & $3+$ & 4 & $3+$ & $3+$ & 4 & 3 & 3 \\
\hline 83 & $\operatorname{Lr} 26^{\mathrm{c}}$ & 4 & 4 & 4 & 4 & 4 & 4 & 4 & 4 & 4 & 4 & 3 & 3 & 3 & 3 & 3 & 2 & 3 \\
\hline
\end{tabular}


combination, were identified in 26 cultivars, while the remaining 57 genotypes likely contained unknown $L r$ gene(s) or lacked detectable $L r$ genes.

Lr26 was present in 20 cultivars. Thirteen cultivars contained only $L r 26$ because they were resistant with two $L r 26$ avirulent pathotypes (TGGT and FGMT) and susceptible with the other 16 pathotypes. Three cultivars, Lian 0536, Sunong 6, and Xuzhou 23, contained Lr26 combined with $L r l$ because they showed resistance to $L r 26$ and $\mathrm{Lrl}$ avirulent pathotypes. Based on their resistant responses to other pathotypes, four genotypes, Huaimai 21, Nanong 3519, Wanmai 47, and Yangfumai 3, had $L r 26$ and other $L r$ genes in combination. All genotypes postulated with $L r 26$ were confirmed by molecular marker for $L r 26$ (Table 3). Eight cultivars were found to have $L r l$ because they were resistant to eight $L r l$ avirulent pathotypes (FHPR, FHJQ1, FHJQ2, KHSS, FHTR, FHHT1, FHHT2, FHTT, and FGMT) (Tables 2 and 3). All cultivars postulated to contain $\operatorname{Lrl}$ were also confirmed by the molecular marker for $\mathrm{Lrl}$.

Four cultivars, viz. Huaimai 21, Nannong 3519, Yangfumai 2, and Yangfumai 3, contained $L r 13$ because they had intermediate reactions to four Lr13 avirulent pathotypes (PHTT2, FHHT1, FHTT, and FGMT). Lr13 and Lr26 were present in Yangfumai 3. Huaimai 21 and Nannong 3519 were found to contain $L r 3 k a, L r 1, L r 26$, and $L r 13$ genes in combination because they were resistant to all avirulent pathotypes to Lr3ka, Lrl, Lr26, and Lrl3.

All the avirulent pathotypes to $\operatorname{Lr} 17$ were also avirulent to $\operatorname{Lrl}$. Therefore, $L r 17$ could not be postulated in the cultivars with $L r l$.

Lr10 was probably present in Wanmai 33, Wanmai 47, and Xumai 4036 because they gave intermediate ITs to $L r 10$ avirulent pathotype PHSL. Lr1O in these cultivars was also confirmed by molecular marker for $\operatorname{Lr} 10$.

Wanmai 47 contained $L r 2 b, L r 21, L r 10$, and $L r 26$ as it displayed low or intermediate ITs with all avirulent pathotypes to $L r 2 b, \operatorname{Lr} 21$, Lr10, and Lr26. Lrll and Lrl were found in Su 553 as it showed low or intermediate ITs to all the $L r 11$ and $L r l$ avirulent pathotypes.

Xumai 31 and Xumai 4036 were resistant to most of $P t$ pathotypes, and their resistance could not be attributed to any known $\mathrm{Lr}$ gene. Therefore, these two cultivars appear to contain unknown $\mathrm{Lr}$ genes.

Fifty-six cultivars showed high ITs to all tested $P t$ pathotypes, as did differential lines carrying the resistance genes $\operatorname{Lr} 2 c, \operatorname{Lr} 3, \operatorname{Lr} 16$,
$L r B, L r 3 b g, L r 14 b$, and $L r 33$. Therefore, it was impossible to postulate $L r$ genes in these cultivars.

Twelve STS and SCAR molecular markers closely linked to $L r l$, Lr9, Lr10, Lr 19, Lr20, Lr24, Lr26, Lr34, Lr37, and Lr46 genes were used to genotype the 83 wheat cultivars (Table 4). The presence of $L r 1, L r 26$, and $L r 10$ were confirmed by gene postulation and molecular marker analysis. All cultivars lacked $\operatorname{Lr} 9, \operatorname{Lr} 19, \operatorname{Lr} 20$, and $\operatorname{Lr} 24$ based on the seedling reaction and molecular marker genotyping. It was not possible to postulate $L r 34, L r 37$, and $L r 46$ in the seedling tests because all are APR genes. Therefore, the molecular markers for these three APR genes were used to test all the cultivars. The results revealed that $L r 46$ was detected in 18 cultivars followed by $L r 34$ and $L r 37$, each present in four cultivars.

The combined results of gene postulation and molecular marker genotyping indicated that $12 \mathrm{Lr}$ genes, namely $\mathrm{Lrl}, \mathrm{Lr} 26, \mathrm{Lr} 3 \mathrm{ka}$, Lr11, Lr10, Lr2b, Lr13, Lr21, Lr34, Lr37, Lr44, and Lr46 either singly or in combination were identified in 41 cultivars, whereas any known $L r$ genes could not be found in the remaining 42 genotypes.

Slow rusting resistance. The analysis of variance showed significant differences between cultivars and environments for FDS in the field (at $P=0.05$ ) (Table 5). This indicated that slow rusting resistance was influenced by cultivar and environment. There were not significant differences between replication, cultivar-environment, and cultivar-replication interactions.

In both cropping seasons, there was good development of leaf rust disease because Zhengzhou 5389 (susceptible check) scored FDS value of 85 and $95 \%$ in the 2014-15 and 2015-16 cropping seasons, respectively (Table 6). On the other hand, SAAR (slow rusting check) scored FDS value of 1 and 3\% in both cropping seasons, respectively. Seventeen cultivars were susceptible to the mixed pathotypes at the seedling stage but showed low FDS value at the field across all the environments (Table 6).

\section{Discussion}

Postulation of seedling effective $L r$ genes was performed based on the gene-for-gene specificity concept described by Flor (1956). This enables one to quickly identify the genes existing in wheat cultivars with diverse genetic backgrounds (Mebrate et al. 2008).

In the present study, $L r 26$ was the most commonly identified $L r$ gene among the 83 tested cultivars. The presence of $L r 26$ may relate

Table 4. PCR primers and their conditions for detecting leaf rust resistance $(L r)$ genes as well as specific fragment sizes

\begin{tabular}{|c|c|c|c|c|c|c|}
\hline$L r$ gene & Marker type & Primer & Sequence of primer $\left(5^{\prime} \rightarrow 3^{\prime}\right)$ & $\begin{array}{l}\text { Annealing } \\
\text { temp. }\left({ }^{\circ} \mathrm{C}\right)\end{array}$ & $\begin{array}{l}\text { Size } \\
\text { (bp) }\end{array}$ & Reference \\
\hline \multirow[t]{2}{*}{$\overline{L r 1}$} & STS & WR003F & GGGACAGAGACCTTGGTGGA & 65 & 760 & Cloutier et al. 2007 \\
\hline & & WR003R & GAC GATGATGATTTGCTGCTGG & & & \\
\hline \multirow[t]{2}{*}{$\operatorname{Lr} 9$} & STS & $\mathrm{J} 13 / 1$ & TCCTTTTATTCCGCACGCCGG & 66 & 1100 & Schachermayr et al. 1994 \\
\hline & & $\mathrm{J} 13 / 2$ & CСАCACTACCCCAAAGAGAG & & & \\
\hline \multirow[t]{2}{*}{$\operatorname{Lr} 10$} & STS & Lrk10D1 & GAAGCCCTTCGTCTCATCTG & 58 & 282 & Schachermayr et al. 1997 \\
\hline & & Lrk10D2 & TTGATTCATTGCAGATGAGATCACG & & & \\
\hline \multirow[t]{2}{*}{$\operatorname{Lr} 19$} & SCAR & SCS265 F & GGCGGATAAGCAGAGCAGAG & 65 & 512 & Gupta et al. 2005 \\
\hline & & SCS265 R & GGCGGATAAGTGGGTTATGG & & & \\
\hline \multirow[t]{2}{*}{$\operatorname{Lr} 19$} & SCAR & SCS253 F & GCTGGTTCCACAAAGCAAA & 60 & 736 & Gupta et al. 2005 \\
\hline & & SCS253 R & GGCTGGTTCCTTAGATAGGTG & & & \\
\hline \multirow[t]{2}{*}{$\operatorname{Lr} 20$} & STS & STS638-L & ACAGCGATGAAGCAATGAAA & 60 & 542 & Neu et al. 2002 \\
\hline & & STS638-R & GTCCAGTTGGTTGATGGAAT & & & \\
\hline \multirow[t]{2}{*}{$\operatorname{Lr} 24$} & STS & Lr24 J 9/1 & TCTAGTCTGTACATGGGGGC & 57 & 310 & Schachermayr et al. 1995 \\
\hline & & Lr24 J 9/2 & TGGCACATGAACTCCATACG & & & \\
\hline \multirow[t]{2}{*}{$\operatorname{Lr} 26$} & STS & Glu-B3F & GGTACCAACAACAACAACCC & 65 & 210 & de Froidmont 1998 \\
\hline & & Glu-B3R & GTTGCTGCTGAGGTTGGTTC & & & \\
\hline \multirow[t]{2}{*}{$\operatorname{Lr} 26$} & STS & $\omega$-secalin F & ACC TTCCTCATCTTTGTCCT & 65 & 1076 & Chai et al. 2006 \\
\hline & & $\omega$-secalin R & CCGATGCCTATACCACTACT & & & \\
\hline \multirow[t]{2}{*}{$\operatorname{Lr} 34$} & STS & $\operatorname{csLV} 34 \mathrm{~F}$ & GTTGGTTAAGACTGGTGATGG & 58 & 150 & Dyck 1987 \\
\hline & & $\operatorname{csLV} 34 \mathrm{R}$ & TGCTTGCTATTGCTGAATAGT & & & \\
\hline \multirow[t]{2}{*}{$\operatorname{Lr} 37$} & STS & VENTRIUP & AGGGGCTACTGACCAAGGCT & 65 & 259 & Bariana and McIntosh 1993 \\
\hline & & LN2 & TGCAGCTACAGCAGTATGTACACAAAA & & & \\
\hline \multirow[t]{2}{*}{ Lr46 } & STS & csLV46G22F & AGG GAAAAGACATCTTTTTTTTC & 58 & 335 & R. P. Singh et al. 1998 \\
\hline & & csLV46G22R & CGACCGACTTCGGGTTC & & & \\
\hline
\end{tabular}


more to its connotation with widespread adaptability and higher yield rather than the resistance it confers to avirulent $P t$ pathotypes (Pathan and Park 2006; Zeller and Hsam 1983). This gene was overcome by $P t$ in many wheat producing areas of the world including North America (Kolmer 1996), Europe (Bartos et al. 1984), South America (Huerta-Espino 1992), the Indian subcontinent (Nayar et al. 1991), South Africa (Pretorius et al. 1990), and China (Li et al. 2010; R. P. Singh et al. 1999). Li et al. (2010) and He et al. (2001) reported that in the early 1970s, the translocation of 1BL/1RS with $\operatorname{Yr} 9$ and Lr26 was introduced to Chinese wheat breeding programs through the introduction of Lovrin 10, Lovrin 13, Predgornaia 2, Kavkaz, and Neuzuch wheat germplasm. Li et al. (2010) identified 44 cultivars containing Lr26 among 102 wheat lines, including Huaimai 18 which was confirmed by this research. According to pedigree analysis, Lr26 in Huaimai 18 and Xumai 29 might be derived from Zhengzhou 891 and Zhoumai 9, respectively (Table 1), because Zhengzhou 891 and Zhoumai 9 carried Lr26 (R. P. Singh et al. 1999). Lr26 in Yangfumai 3 might be derived from Yangmai 158 (Table 1), because Yangmai 158 carried $L r 26$ and it was one of the parents of Yangfumai 3 (He et al. 2001). In validating the present study, Ren et al. (2015) also reported that Lianmai 2 contained $L r 26$.

R. P. Singh et al. (1999) reported $L r l$ was present in 13 cultivars among a collection of 163 Chinese wheat cultivars inoculated with 14 Pt pathotypes. Li et al. (2010) found that seven cultivars carried

Table 5. Analysis of variance of final disease severity (FDS, \%) in 85 wheat genotypes, including slow rusting cultivar SAAR and susceptible Zhengzhou 5389 checks, tested in the 2014-15 and 2015-16 growing seasons

\begin{tabular}{llrrrr}
\hline Parameter & Source of variation & df & MS & $\boldsymbol{F}$ value & $\boldsymbol{P}$ \\
\hline FDS & Cultivar & 84 & 13350.08 & $48.22^{\mathrm{a}}$ & $<0.0001$ \\
& Environment & 1 & 7160.22 & $25.86^{\mathrm{a}}$ & $<0.0001$ \\
& Replication & 1 & 936.70 & 3.38 & 0.0660 \\
& Cultivar*Environment & 84 & 247.39 & 0.89 & 0.7445 \\
& Cultivar*Replication & 84 & 133.09 & 0.48 & 1.0000 \\
Error & 2870 & 276.88 & & \\
\hline
\end{tabular}

a Significant at the 0.05 level of probability.
Lrl from 102 tested lines with 24 pathotypes. Virulence for $L r l$ is common in China (Li et al. 2010; R. P. Singh et al. 1999), Iran (Boroujeni et al. 2011), and Australia (D. Singh et al. 2001). In the present study, $L r l$ in combination with other resistance genes was identified in seven cultivars (Table 3). Lrl in Xuzhou 23 might be derived from UP301, based on its pedigree analysis (R. P. Singh and A. K. Gupta 1991). $L r l$ in Su 553 and Huaimai 21 might be derived from Yannong 19 (Li et al. 2010) and Yumai 54 (R. P. Singh et al. 1999), respectively (Table 1 ).

The seedling resistance in 56 cultivars could not be determined because all of them showed high ITs with most of the pathotypes. It may be better to use different pathotypes with diverse pathogenicity or additional differential lines with other resistance genes to postulate the genes in these cultivars.

Although the seedling $L r$ genes were postulated on the basis of gene-for-gene strategy, there was observable limitation to this approach. It was not possible to identify all the $L r$ genes in the cultivars due to limitation of virulence in $P t$ pathotypes. Detecting $L r$ genes using molecular markers was more efficient and economic than gene postulation. In the present study, the identification of $L r 1, L r 26$, Lr10, Lr34, Lr37, and Lr46 using molecular markers was vigorous and stable. Therefore, the molecular markers for above listed $\mathrm{Lr}$ genes may be very useful in MAS for developing wheat cultivars for resistance to leaf rust in China.

All 17 cultivars identified to carry slow rusting resistance were also tested with $18 P t$ pathotypes at seedling stage (Tables 3 and 6). Nine cultivars, viz. Huaimai 21, Lian 0536, Nannong 3519, Sunong 6, Wanmai 46, Wanmai 47, Xu 9069, Xumai 26, and Xumai 29 contained Lr26. Huaimai 21, Lian 0536, Nannong 3519, Sunong 6, and Wanmai 47 had other known $L r$ genes. Cultivar Wanmai 33 contained $\mathrm{Lr} 10$ and $\mathrm{Lr} 44$ in combination. Three cultivars, Pengxuan 3, Sumai 3, and Xuzhou 438, contained Lr34 and Lr46 in combination. The mixed pathotype was virulent to all these genotypes at the seedling stage and the slow rusting resistances in these cultivars might be from $L r 34, L r 46$, and other APR genes. Unknown APR genes might be present in four cultivars (Nannong 02y293, Wanmai 53, Xumai 30, and Yangmai 12) that were found to have slow rusting resistance at both field trials.

Table 6. Seedling infection types (ITs) ${ }^{\mathrm{a}}$ with mixed Puccinia triticina Eriks (Pt) pathotype in the seedling test and final disease severity (FDS, \%) in field experiments in Baoding and Zhoukou in 2014-15 and 2015-16 growing seasons for wheat cultivars with slow rusting resistance to leaf rust

\begin{tabular}{|c|c|c|c|c|c|c|c|}
\hline Line no. ${ }^{\mathbf{b}}$ & Cultivar & $\mathbf{A P R}^{c}$ genes & $\begin{array}{l}\text { Seedling ITs to } \\
\text { mixed pathotype }\end{array}$ & $\begin{array}{c}2014-15 \\
\text { Baoding FDS (\%) }\end{array}$ & $\begin{array}{c}2015-16 \\
\text { Baoding FDS }(\%)\end{array}$ & $\begin{array}{c}2014-15 \\
\text { Zhoukou FDS (\%) }\end{array}$ & $\begin{array}{c}2015-16 \\
\text { Zhoukou FDS (\%) }\end{array}$ \\
\hline 7 & Huaimai 21 & - & 3 & 5 & 3 & 1 & 10 \\
\hline 10 & Lian 0536 & - & 3 & 12.5 & 1 & 12.5 & 3 \\
\hline 14 & Nannong 02y293 & - & 3 & 10 & 12.5 & 7.5 & 12.5 \\
\hline 16 & Nannong 3519 & - & 3 & 7.5 & 10 & 1 & 3 \\
\hline 33 & Pengxuan 3 & Lr34, Lr46 & $3+$ & 10 & 10 & 5 & 12.5 \\
\hline 36 & Sumai 3 & $L r 34, L r 46$ & 4 & 3 & 15 & 3 & 10 \\
\hline 37 & Sunong 6 & $\operatorname{Lr} 37$ & 3 & 5 & 5 & 7.5 & 12.5 \\
\hline 41 & Wanmai 33 & - & 4 & 10 & 5 & 12.5 & 7.5 \\
\hline 43 & Wanmai 46 & - & 4 & 15 & 5 & 10 & 3 \\
\hline 44 & Wanmai 47 & - & 4 & 10 & 12.5 & 5 & 15 \\
\hline 47 & Wanmai 53 & - & 3 & 7.5 & 15 & 12.5 & 15 \\
\hline 50 & Xu 9069 & - & 4 & 5 & 15 & 12.5 & 10 \\
\hline 54 & Xumai 26 & - & $3+$ & 15 & 10 & 7.5 & 15.5 \\
\hline 56 & Xumai 29 & - & $3+$ & 10.5 & 15 & 15 & 10 \\
\hline 58 & Xumai 31 & - & 4 & 7.5 & 7.5 & 8 & 3 \\
\hline 63 & Xuzhou 438 & Lr34, Lr46 & 4 & 7.5 & 12.5 & 5 & 15 \\
\hline \multirow[t]{4}{*}{69} & Yangmai 12 & - & 3 & 5 & 5 & 15 & 12.5 \\
\hline & Saar $^{\mathrm{d}}$ & - & 4 & 1 & 3 & 1 & 3 \\
\hline & Zhengzhou $5389^{\mathrm{e}}$ & - & 4 & 80 & 95 & 85 & 95 \\
\hline & LSD & $(P=0.05)$ & & & 12.35 & & \\
\hline
\end{tabular}

\footnotetext{
${ }^{a}$ According to the $0-4$ Stakman scale as modified by Roelfs et al. (1992).

${ }^{\mathrm{b}}$ Line numbers correspond to those in Table 1 .

c Adult plant resistance genes based on molecular marker.

${ }^{\mathrm{d}}$ Slow rusting check.

e Susceptible check.
} 
The results of this study are useful to incorporate the resistance genes from the source identified here into the Chinese facultative wheat genotypes to improve the genetic diversity of cultivars and reduce future leaf rust damage in China.

\section{Acknowledgments}

The authors are very grateful to Professor R. F. Park at University of Sydney for critical review of this manuscript. This study was supported by the key project of Hebei Applied Foundation Research Plan (11960145D), and the National Science Foundation of China (31361140367 and 31571662).

\section{Literature Cited}

Bariana, H. S., and McIntosh, R. A. 1993. Cytogenetic studies in wheat. XV. Location of rust resistance genes in VPM1 and their genetic linkage with other disease resistance genes in chromosome 2A. Genome 36:476-482.

Bartos, P., Stuchlikova, E., and Kubova, R. 1984. Wheat leaf rust epidemics in Czechoslovakia in 1983. Cereal Rusts Bull. 12:40-41.

Boroujeni, F. R., Arzani, A., Afshari, F., and Torabi, M. 2011. Postulation of leaf rust resistance genes in Iranian wheat cultivars and breeding lines. Can. J. Plant Pathol. 33:550-558.

Caldwell, R. M. 1968. Breeding for general and/or specific plant disease resistance. Pages 263-272 in: Proc. 3rd Int. Wheat Genetics Sympos. K. W. Findlay and K. W. Shepherd, eds. Australian Acad Sci, Canberra, Australia.

Chai, J. F., Zhou, R. H., Jia, J. Z., and Liu, X. 2006. Development and application of a new codominant PCR marker for detecting 1BL-1RS wheat-rye chromosome translocations. Plant Breed. 125:302-304.

Cloutier, S., McCallum, B. D., Loutre, C., Banks, T. W., Wicker, T., Feuillet, C., Keller, B., and Jordan, M. C. 2007. Leaf rust resistance gene $L r l$, isolated from bread wheat (Triticum aestivum L.) is a member of the large psr567gene family. Plant Mol. Biol. 65:93-106.

de Froidmont, D. 1998. A co-dominant marker for the 1BL/1RS wheat-rye translocation via multiplex PCR. J. Cereal Sci. 27:229-232.

Dong, J. G. 2001. Agricultural Plant Pathology. China Agriculture Press, Beijing.

Dubin, H. J., Johnson, R., and Stubbs, R. W. 1989. Postulated gene-for-gene resistant to stripe rust in selected CIMMYT and related wheat. Plant Dis. 73: $472-475$.

Dubin, H. J., and Torres, E. 1981. Causes and consequences of the 1976-1977 wheat leaf rust epidemic in Northwest Mexico. Annu. Rev. Phytopathol. 19:41-49.

Dyck, P. L. 1987. The association of gene for leaf rust resistance with the chromosome 7D suppressor of stem rust resistance in common wheat. Genome 29:467-469.

Flor, H. H. 1956. The complementary gene systems in flax and flax rust. Adv. Genet. 8:29-54.

Gill, K. S., Lubbers, E. L., Gill, B. S., Raupp, W. J., and Cox, T. S. 1991. A genetic linkage map of Triticum tauschii (DD) and its relationship to the D genome of bread wheat (AABBDD). Genome 34:362-374.

Gupta, S. K., Charpe, A., Koul, S., Haque, Q., and Prabhu, K. 2006a. Development and validation of SCAR markers cosegregating with an Agropyron elongatum derived leaf rust resistance gene Lr24 in wheat. Euphytica 150:233-240.

Gupta, S. K., Charpe, A., Koul, S., Prabhu, K. V., and Haque, Q. M. 2005. Development and validation of molecular markers linked to an Aegilops umbellulata-derived leaf-rust-resistance gene, $\operatorname{Lr} 9$, for marker-assisted selection in bread wheat. Genome 48:823-830

Gupta, S. K., Charpe, A., Prabhu, K. V., and Haque, Q. M. 2006b. Identification and validation of molecular markers linked to the leaf rust resistance gene Lr19 in wheat. Theor. Appl. Genet. 113:1027-1036.

He, Z. H., Rajaram, S., Xin, Z. Y., and Zhang, G. Z. 2001. A history of wheat breeding in China. CIMMYT, D.F., Mexico.

Helguera, M., Khan, I. A., Kolmer, J., Lijavetzky, D., Zhong-qi, L., and Dubcovsky, J. 2003. PCR assay for the Lr37-Yr17-Sr38 cluster of rust resistance genes and their use to develop isogenic hard red spring wheat lines. Crop Sci. 43:1839-1847.

Herrera-Foessel, S. A., Lagudah, E. S., Huerta-Espino, J., Hayden, M. J., Bariana, H. S., Singh, D., and Singh, R. P. 2011. New slow-rusting leaf rust and stripe rust resistance genes $L r 67$ and $Y r 46$ in wheat are pleiotropic or closely linked. Theor. Appl. Genet. 122:239-249.

Herrera-Foessel, S. A., Singh, R. P., Huerta-Espino, J., Rosewarne, G. M., Periyannan, S. K., Viccars, L., Calvo-Salazar, V., Lan, C., and Lagudah, E. S. 2012. Lr68: a new gene conferring slow rusting resistance to leaf rust in wheat. Theor. Appl. Genet. 124:1475-1486.

Hiebert, C. W., Thomas, J. B., McCallum, B. D., Humphreys, D. G., DePauw, R. M., Hayden, M. J., Mago, R., Schnippenkoetter, W., and Spielmeyer, W. 2010. An introgression on wheat chromosome 4DL in RL6077 (Thatcher*6/ PI 250413) confers adult plant resistance to stripe rust and leaf rust ( $\operatorname{lr} 67)$. Theor. Appl. Genet. 121:1083-1091.

Huerta-Espino, J. 1992. Analysis of Wheat Leaf and Stem Rust Virulence on a Worldwide Basis. Ph.D. Thesis, The University of Minnesota, Minneapolis, MN, U.S.A.

Hysing, S. C., Singh, R. P., Huerta-Espino, J., Merker, A., Liljeroth, E., and Diaz, O. 2006. Leaf rust (Puccinia triticina) resistance in wheat (Triticum aestivum) cultivars grown in Northern Europe 1992-2002. Hereditas 143:1-14.
Khan, M. H., Bukhari, A., Dar, Z. A., and Rizvi, S. M. 2013. Status and strategies in breeding for rust resistance in wheat. Agric. Sci. 04:292-301.

Kolmer, J. A. 1996. Physiologic specialization of Puccinia recondita f. sp. tritici in Canada in 1996. Can. J. Plant Pathol. 20:176-181.

Li, Z. F., Lan, C. X., He, Z. H., Singh, R. P., Rosewarne, G. M., Chen, X. M., and Xia, X. C. 2014. Overview and application of QTL for adult plant resistance to leaf rust and powdery mildew in wheat. Crop Sci. 54:1907-1925.

Li, Z. F., Xia, X. C., He, Z. H., Li, X., Zhang, L. J., Wang, H. Y., Meng, Q. F., Yang, W. X., Li, G. Q., and Liu, D. Q. 2010. Seedling and slow rusting resistance to leaf rust in Chinese wheat cultivars. Plant Dis. 94:45-53.

Long, D. L., and Kolmer, J. A. 1989. A North American system of nomenclature for Puccinia recondita f. sp. tritici. Phytopathology 79:525-529.

Maaroof, E. M., Singh, R. P., Julio, H. E., and Atiq, R. 2005. Resistance of some Iraqi bread wheat cultivars to Puccinia triticina. Phytopathol. Mediterr. 44: $247-255$

Mago, R., Spielmeyer, W., Lawrence, G. J., Lagudah, E. S., Ellis, J. G., and Pryor, A. 2002. Identification and mapping of molecular markers linked to rust resistance genes located on chromosome 1RS of rye using wheat-rye translocation lines. Theor. Appl. Genet. 104:1317-1324.

McDonald, B. A., and Linde, C. 2002. Pathogen population genetics, evolutionary potential, and durable resistance. Annu. Rev. Phytopathol. 40:349-379.

McIntosh, R. A., Dubcovsky, J., Rogers, W. J., Morris, C., Appels, R., and Xia, X. C. 2016. Catalogue of gene symbols for wheat: 2015-2016 supplement. Online: https://shigen.nig.ac.jp/wheat/komugi/genes/macgene/supplement2015.pdf

McIntosh, R. A., Wellings, C. R., and Park, R. F. 1995. Wheat Rusts - An Atlas of Resistance Genes. CSIRO Publications, Canberra, Australia.

McIntosh, R. A., Yamazaki, Y., Devos, K. M., Dubcovsky, J., Rogers, J., and Appels, R. 2003. Catalog of gene symbols for wheat. Proc. $10^{\text {th }}$ Int. Wheat Genet. Symposium, Vol. 1. Instituto Sperimentale per la Cerealcoltura, Rome, Italy.

McVey, D. V., and Long, D. L. 1993. Genes for leaf rust resistance in hard red winter wheat cultivars and parental lines. Crop Sci. 33:1373-1381.

Mebrate, S. A., Dehne, H. W., Pillen, K., and Oerke, E. C. 2008. Postulation of seedling leaf rust resistance genes in selected Ethiopian and German bread wheat cultivars. Crop Sci. 48:507-516.

Nayar, S. K., Prashar, M., Kumar, J., Bhardwaz, S. C., and Bhatnagar, R. 1991 Pathotypes of Puccinia recondita f. sp. tritici virulent for $\operatorname{Lr} 26$ (1BL/1RS translocation) in India. Cer. Res. Comm. 19:327-331

Neu, C., Stein, N., and Keller, B. 2002. Genetic mapping of the Lr20-PmI resistance locus reveals suppressed recombination on chromosome arm 7AL in hexaploid wheat. Genome 45:737-744.

Pathan, A. K., and Park, R. F. 2006. Evaluation of seedling and adult plan resistance to leaf rust in European wheat cultivars. Euphytica 149:327-342.

Peterson, R. F., Campbell, A. B., and Hannah, A. E. 1948. A diagrammatic scale for estimating rust intensity of leaves and stem of cereals. Can. J. Res. 26 496-500.

Pink, D. A. C. 2002. Strategies using genes for non-durable disease resistance Euphytica 124:227-236.

Pretorius, Z. A., Roux, J. L., and Drijepondt, S. C. 1990. Occurrence and pathogenicity of Puccinia recondita f. sp. tritici on wheat in South Africa during 1988. Phytophylactica 22:225-228.

Prins, R., Groenewald, J., Marais, G., Snape, J., and Koebner, R. 2001. AFLP and STS tagging of $\operatorname{Lr} 19$, a gene conferring resistance to leaf rust in wheat. Theor. Appl. Genet. 103:618-624.

Ren, X. L., Liu, T. G., Liu, B., Gao, L., and Chen, W. Q. 2015. Postulation of seedling leaf rust resistance genes in 84 Chinese winter wheat cultivars. J. Integr. Agric. 14:1992-2001.

Roelfs, A. P., Singh, R. P., and Saari, E. E. 1992. Rust diseases of wheat: Concepts and methods of disease management. CIMMYT, Mexico, DF. Online: http:// repository.cimmyt.org/xmlui/handle/10883/1153

Schachermayr, G., Feuillet, C., and Keller, B. 1997. Molecular markers for the detection of the wheat leaf rust resistance gene $\operatorname{LrlO}$ in diverse genetic backgrounds. Mol. Breed. 3:65-74.

Schachermayr, G., Siedler, H., Gale, M. D., Winzeler, H., Winzeler, M., and Keller, B. 1994. Identification and localization of molecular markers linked to the $L r 9$ leaf rust resistance gene of wheat. Theor. Appl. Genet. 88: $110-115$

Schachermayr, G. M., Messmer, M. M., Feuillet, C., Winzeler, H., Winzeler, M., and Keller, B. 1995. Identification of molecular markers linked to the Agropyron elongatum-derived leaf rust resistance gene $L r 24$ in wheat. Theor. Appl. Genet. 90:982-990.

Singh, D., Park, R. F., and McIntosh, R. A. 2001. Postulation of leaf (brown) rust resistance genes in 70 wheat cultivars grown in the United Kingdom. Euphytica 120:205-218

Singh, R. P. 1992. Genetic association of leaf rust resistance gene Lr34 with adult plant resistance to stripe rust in bread wheat. Phytopathology 82:835-838.

Singh, R. P., Chen, W. Q., and He, Z. H. 1999. Leaf rust resistance of spring, facultative, and winter wheat cultivars from China. Plant Dis. 83:644-651.

Singh, R. P., and Gupta, A. K. 1991. Genes for leaf rust resistance in Indian and Pakistani wheat tested with Mexican pathotypes of Puccinia recondita f. sp. tritici. Euphytica 57:27-36

Singh, R. P., Mujeeb-Kazi, A., and Huerta, E. J. 1998. Lr46: A gene conferring slow rusting resistance to leaf rust in wheat. Phytopathology 88:890-894. 
Singh, R. P., and Rajaram, S. 1991. Resistance to Puccinia recondita f. sp. tritici in 50 Mexican bread wheat cultivars. Crop Sci. 31:1472-1479.

Sokal, R. R., and Rohlf, F. J. 1989. Introduction to Biostatistics, 2nd Ed. W. H. Freeman and Co., New York.

Spielmeyer, W., McIntosh, R. A., Kolmer, J., and Lagudah, E. S. 2005. Powdery mildew resistance and $\operatorname{Lr} 34 / \mathrm{Yr} 18$ genes for durable resistance to leaf and stripe rust cosegregate at a locus on the short arm of chromosome 7D of wheat. Theor. Appl. Genet. 111:731-735.

Yuan, J. H., Liu, T. G., and Chen, W. Q. 2007. Postulation of leaf rust resistance genes in 47 new wheat cultivars at seedling stage. Sci. Agric. Sin. 40:1925-1935.
Zeller, F. J., and Hsam, S. L. K. 1983. Broadening the genetic variability of cultivated wheat by utilizing rye chromatin. Pages $161-173$ in: Proc $6^{\text {th }}$ Intl Wheat Genet Symp. Faculty of Agriculture, Kyoto University, Japan.

Zhao, X. L., Zheng, T. C., Xia, X. C., He, Z. H., Liu, D. Q., Yang, W. X., Yin, G. H., and Li, Z. F. 2008. Molecular mapping of leaf rust resistance gene LrZH84 in Chinese wheat line Zhou 8425B. Theor. Appl. Genet. 117: 1069-1075.

Zhou, H. X., Xia, X. C., He, Z. H., Li, X., Wang, C. F., Li, Z. F., and Liu, D. Q 2013. Molecular mapping of leaf rust resistance gene $\mathrm{LrNJ97}$ in Chinese wheat line Neijiang 977671. Theor. Appl. Genet. 126:2141-2147. 